\title{
Nut Consumption Is Associated with Lower Risk of Metabolic Syndrome and Its Components in Type 1 Diabetes
}

\author{
Aila J. Ahola ${ }^{1,2,3}$, Carol M. Forsblom ${ }^{1,2,3}$, Valma Harjutsalo ${ }^{1,2,3,4}$ and Per-Henrik Groop ${ }^{1,2,3,5, *,+}$ on behalf of the \\ FinnDiane Study Group \\ 1 Folkhälsan Institute of Genetics, Folkhälsan Research Center, 00290 Helsinki, Finland; \\ aila.ahola@helsinki.fi (A.J.A.); carol.forsblom@hus.fi (C.M.F.); valma.harjutsalo@helsinki.fi (V.H.) \\ 2 Department of Nephrology, University of Helsinki and Helsinki University Hospital, 00290 Helsinki, Finland \\ 3 Research Program for Clinical and Molecular Metabolism, Faculty of Medicine, University of Helsinki, \\ 00014 Helsinki, Finland \\ 4 National Institute for Health and Welfare, 00300 Helsinki, Finland \\ 5 Department of Diabetes, Central Clinical School, Monash University, Melbourne, VIC 3004, Australia \\ * Correspondence: per-henrik.groop@helsinki.fi; Tel.: +358-500-430-436 \\ + FinnDiane Study Group refers to acknowledgments.
}

Citation: Ahola, A.J.; Forsblom, C.M.; Harjutsalo, V.; Groop, P.-H., on behalf of the FinnDiane Study Group. Nut Consumption Is Associated with Lower Risk of Metabolic Syndrome and Its Components in Type 1 Diabetes. Nutrients 2021, 13, 3909. https://doi.org/10.3390/nu13113909

Academic Editor: Elvira Verduci

Received: 6 October 2021

Accepted: 29 October 2021

Published: 30 October 2021

Publisher's Note: MDPI stays neutral with regard to jurisdictional claims in published maps and institutional affiliations.

Copyright: (c) 2021 by the authors Licensee MDPI, Basel, Switzerland. This article is an open access article distributed under the terms and conditions of the Creative Commons Attribution (CC BY) license (https:// creativecommons.org/licenses/by/ $4.0 /)$.

\begin{abstract}
Although nut consumption has been associated with several health benefits, it has not been investigated in individuals with type 1 diabetes. Therefore, our aim was to assess nut consumption and its association with metabolic syndrome in adult individuals with type 1 diabetes taking part in the Finnish Diabetic Nephropathy Study. The nut intake of the 1058 participants was assessed from 3-day food records that were completed twice, and the number of weekly servings, assuming a serving size of $28.4 \mathrm{~g}$, was calculated. Metabolic syndrome was defined as the presence of $\geq 3$ of the cardiovascular risk factors: central obesity, high blood pressure $(\geq 130 / 85 \mathrm{mmHg}$ or use of antihypertensive medication), high triglyceride concentration $(\geq 1.70 \mathrm{mmol} / \mathrm{L}$ or use of lipidlowering medication), low HDL-cholesterol concentration $(<1.00 \mathrm{mmol} / \mathrm{L}$ in men and $<1.30 \mathrm{mmol} / \mathrm{L}$ in women or use of lipid-lowering medication), and hyperglycaemia. Overweight/obesity was defined as a $\mathrm{BMI} \geq 25 \mathrm{~kg} / \mathrm{m}^{2} . \mathrm{HbA}_{1 \mathrm{c}}>59 \mathrm{mmol} / \mathrm{mol}(>7.5 \%)$ was used as a criterion for suboptimal glycaemic control. Of the 1058 (mean age 46 years, 41.6\% men) participants, 689 (54.1\%) reported no nut intake. In the remaining sample, the median weekly nut intake was $40.8 \mathrm{~g}$. In the adjusted models, higher nut intake, as the continuous number of weekly servings and the comparison of those with $<2$ and $\geq 2$ weekly servings, was associated with lower metabolic syndrome score, waist circumference, $\mathrm{HbA}_{1 \mathrm{c}}$, and BMI. Nut consumption as a continuous variable was negatively associated with the presence of metabolic syndrome, its blood pressure, triglyceride, and HDL-cholesterol components, and suboptimal glycaemic control. Consumption of $\geq 2$ weekly servings was associated with lower odds of suboptimal glycaemic control (by 51.5\%), overweight/obesity (by $33.4 \%$ ), and metabolic syndrome (by 51.8\%) and meeting the waist (by 37.3\%), blood pressure (by $44.5 \%$ ), triglyceride (by $37.7 \%$ ), and HDL-cholesterol (by $36.2 \%$ ) components of the metabolic syndrome. In conclusion, a weekly nut intake of $\geq 2$ servings was beneficially associated with all the components of the metabolic syndrome in type 1 diabetes. The causality of this association will need to be investigated.
\end{abstract}

Keywords: nut consumption; metabolic syndrome; type 1 diabetes

\section{Introduction}

Nuts, as part of a healthy diet, have gained increasing attention as they are good sources of unsaturated fatty acids, fiber, vegetable protein, minerals, and bioactive compounds [1]. Given that nuts are low in carbohydrates, they minimally contribute to postprandial glycaemia, which is important to individuals with diabetes. However, beyond affecting postprandial glycaemia, nuts also have other beneficial health effects. Amongst others, nut consumption has been associated with a lower risk of coronary arterial disease 
and related mortality [2-4]. Based on the cumulated evidence, the U.S. Food and Drug Administration issued a qualified health claim in 2003 stating that the daily consumption of 1.5 ounces $(42.6 \mathrm{~g}$ ) of most nuts, as part of a healthy diet, may reduce the risk of heart disease [5].

Metabolic syndrome, a cluster of cardiovascular risk factors, is an important cause of morbidity and mortality worldwide [6]. The components of the metabolic syndrome, including hyperglycaemia, high blood pressure, high triglyceride concentrations, low HDL-cholesterol concentrations, and central obesity [7], are also frequently observed in individuals with type 1 diabetes [8]. There is also evidence that metabolic syndrome in type 1 diabetes is associated with an increased risk of long-term vascular complications [9]. Although individuals with type 1 diabetes are at a high risk of adverse vascular events, the potential health effects of nut consumption have not been investigated in this vulnerable patient group. Instead, the association between nut consumption and metabolic syndrome has been investigated in a number of other populations. In the Prevención con Dieta Mediterránea (PREDIMED) trial, in individuals with a high risk of cardiovascular diseases, the consumption of more than three weekly servings of nuts was associated with lower odds of the metabolic syndrome compared to those reporting less than one weekly serving [10]. In the SUN Project with Spanish university graduates, those reporting the consumption of $\geq 2$ weekly servings had a significantly lower risk of future metabolic syndrome compared to the non-consumers [11]. Our aim was, therefore, to assess nut consumption in a welldefined sample of Finnish adults with type 1 diabetes and to investigate the association between nut intake and the presence of metabolic syndrome and its components.

\section{Materials and Methods}

Data for the current analyses were collected from The Finnish Diabetic Nephropathy (FinnDiane) Study, which is an ongoing nation-wide multicenter study for identifying the risk factors for diabetes complications in type 1 diabetes. Since the launch of the FinnDiane Study in 1997, more than 5000 individuals have been recruited at 92 sites, including 5 university hospitals, 16 central hospitals, most of the regional hospitals, and several primary healthcare centers around Finland (see the electronic supplementary material for a list of the centers). The nutrition sub-study of the FinnDiane Study was initiated in 2007; thus, the number of participants in the current study $(n=1058)$ is lower. In this study, type 1 diabetes was defined as the onset of diabetes prior to the age of 40 years with permanent insulin treatment initiated within a year from the diabetes diagnosis. For these analyses, we included data from all adult (age $\geq 18$ years) participants reporting plausible energy intake (3350-16,740 kJ/d or 800-4000 kcal/d). Individuals with an estimated glomerular filtration rate (eGFR) $<30 \mathrm{~mL} / \mathrm{min} / 1.73 \mathrm{~m}^{2}$, undergoing dialysis, or having a renal transplant were excluded. The Ethics Committee of Helsinki and Uusimaa Hospital District approved the study protocol (Ethics committee reference number 491/E5/06). The study was carried out in accordance with the Declaration of Helsinki and its later amendments. Written informed consent was obtained from all individuals prior to study participation.

\subsection{Study Visit}

At the FinnDiane Study visit, participants were thoroughly investigated, as previously explained in detail [12]. Being of importance to the current analyses, waist circumference, weight, and height were measured. Following a 10-min rest, seated blood pressure was measured twice. The mean of the measurements was used in the analyses. Blood was drawn for the subsequent central analyses of serum lipid, lipoprotein, and creatinine concentrations, performed at the Helsinki University Hospital laboratory. Glycated haemoglobin $\left(\mathrm{HbA}_{1 \mathrm{c}}\right)$ was measured locally using a standardized assay. Serum creatinine concentration was used to calculate the eGFR [13]. Current smoking, insulin dosing, and medication use were self-reported on questionnaires. 


\subsection{Outcome Variables}

Metabolic syndrome was defined according to the criteria by Alberti et al. [7]. Accordingly, metabolic syndrome was assumed with the presence of 3 or more of the following criteria: waist circumference $\geq 94 \mathrm{~cm}$ in men and $\geq 80 \mathrm{~cm}$ in women, triglyceride concentration $\geq 1.70 \mathrm{mmol} / \mathrm{L}$ (or use of lipid-lowering medication), HDL-cholesterol concentration $<1.00 \mathrm{mmol} / \mathrm{L}$ in men and $<1.30 \mathrm{mmol} / \mathrm{L}$ in women (or use of lipid-lowering medication), blood pressure $\geq 130 / 85 \mathrm{mmHg}$ (or use of antihypertensive medication), and fasting glucose concentration $\geq 6.11 \mathrm{mmol} / \mathrm{L}$ (or diabetes diagnosis). As all the participants had type 1 diabetes, the total metabolic syndrome score ranged between 1 and 5 . Body mass index (BMI) was treated as a continuous variable, and we additionally divided the participants into those with normal weight (BMI $<25 \mathrm{~kg} / \mathrm{m}^{2}$ ) and those with overweight or obesity (BMI $\geq 25 \mathrm{~kg} / \mathrm{m}^{2}$ ). Glycaemic control, measured as $\mathrm{HbA}_{1 \mathrm{c}}$, was also used both as a continuous variable and as a dichotomous variable. When dichotomizing, suboptimal glycaemic control was defined as $\mathrm{HbA}_{1 \mathrm{c}}>59 \mathrm{mmol} / \mathrm{mol}$ or $>7.5 \%$.

\subsection{Dietary Intake}

In the FinnDiane Study, two separate methods were used to assess dietary intake, as previously described [14]. First, the participants filled out a validated [15] diet questionnaire in which the consumption of the most common food items, in Finland, was reported. Thereafter, the participants twice completed a three-day food record with a 2-3 month interval. The consecutive days for this recording were allocated and comprised of two weekdays and one weekend day. In the record, all the foods and drinks consumed were reported using household measures or information on the food labels to estimate the portion sizes. The continuation of habitual practices during the recording days was emphasized. In the same record, participants also reported their physical activity (type of activity, its strenuousness, and its duration). For the purpose of the current study, the diet questionnaire was used for calculating a diet score, as previously explained in detail [16]. Briefly, the entries in the questionnaire were compared against the Finnish dietary recommendations, and their closer adherence yielded a higher score. AivoDiet software (version 2.0.2.3, AIVO, Turku, Finland) was used to calculate the total energy intake from the data collected with the food records. Data on nut consumption were retrieved from the food records. Here, data on the reported amounts of almonds, Brazil nuts, cashew nuts, hazel nuts, macadamia nuts, pecans, pine nuts, pistachio nuts, walnuts, and, although botanically a legume, peanuts were collected. Based on the food record entries, the weekly amount was calculated for each nut type. For example, if over the six recording days a consumption of $50 \mathrm{~g}$ of cashew nuts was reported, the weekly dose was calculated as $(50 \mathrm{~g} / 6$ days $) \times 7$ days. By adding up the weekly doses of all the individual nuts, we obtained a total weekly nut intake. Using the serving size of $28.4 \mathrm{~g}(1 \mathrm{oz})$, we further calculated a weekly number of servings for each participant. Finally, using the physical activity data reported in the records, the total amount of physical activity as the metabolic equivalent of task (MET) minutes was calculated by multiplying the duration of the activity by the activity- and intensity-specific metabolic equivalent.

\subsection{Statistical Analyses}

Data are presented as frequencies for categorical variables, medians (interquartile ranges) for continuous variables with skewed distribution (normality was assessed with the Kolmogorov-Smirnov test), and means \pm standard deviations for continuous variables with normal distribution. In these respective variables, between-group comparisons were conducted with the Chi-squared test, Mann-Whitney U-test, and independent samples' $t$-test. Data on nut consumption were treated as continuous variables (grams per week and servings per week). In addition, the sample was divided into those weekly consuming $<2$ and $\geq 2$ servings of nuts. Differences in the background variables (sex, age, smoking status, diet score, total energy intake, physical activity, insulin dosing, and eGFR) between these two groups were investigated, and variables with sufficient between-group differ- 
ence $(p<0.1)$ were chosen as confounders for the multivariable models. For sensitivity analyses, we also compared those reporting the consumption of $<1$ and $\geq 1$ weekly servings (results shown in the supplementary material). Generalized linear regression was used to study the associations between nut consumption and the continuous outcome variables (metabolic syndrome score, waist circumference, systolic and diastolic blood pressures, triglyceride and HDL-cholesterol concentrations, $\mathrm{HbA}_{1 \mathrm{c}}$, and $\left.\mathrm{BMI}\right)$. Logistic regression analysis was used to study the associations between nut consumption and the categorical outcome variables (metabolic syndrome, the presence of the individual components of the metabolic syndrome, suboptimal glycaemic control, and the presence of overweight or obesity). Analyses were conducted with IBM SPSS Statistics for Windows, Version 25.0 (IBM, Armonk, NY, USA). A two-tailed $p$-value $<0.05$ was chosen to designate statistical significance.

\section{Results}

Dietary data were available from 1058 individuals (mean \pm standard deviation age $46 \pm 14$ years, $41.6 \%$ men). Since the initiation of the dietary data collection, 1867 individuals had been investigated at the FinnDiane Study visit by the time of data retrieval. Thus, the percentage of individuals completing the food record was $56.7 \%$. Individuals not completing the food records were more frequently men, were younger, and were more frequently current smokers (Supplementary Table S1). In addition, the non-responders had a worse health profile as they more frequently had suboptimal glycaemic control and metabolic syndrome. In addition, they had higher diastolic blood pressure and triglyceride concentration but lower HDL-cholesterol concentration. Instead, the two groups were comparable in their median systolic blood pressure, total cholesterol concentration, and BMI.

In all, 689 (65.1\%) of the sample reported no nut intake. In the remaining sample, the reported median (interquartile range) weekly total nut dose was 40.8 (11.7-115.6) g. Among those reporting nut intake, peanuts were consumed in the highest quantities (27.1 g/week), followed by cashew nuts ( $26.1 \mathrm{~g} /$ week), almonds (13.0 g/week), walnuts (7.2 g/week), hazel nuts (6.8 g/week), pecans ( $2.9 \mathrm{~g}$ /week), macadamia nuts $(0.8 \mathrm{~g} /$ week), pistachio nuts ( $0.7 \mathrm{~g} /$ week), Brazil nuts ( $0.5 \mathrm{~g} /$ week $)$, and pine nuts $(0.2 \mathrm{~g} /$ week).

Those consuming at least two weekly servings $(n=156,14.7 \%)$, were less frequently men, were more physically active, and reported higher total energy intake and lower total insulin dose per body weight compared to those with no or low nut intake (Table 1). Instead, the two groups were comparable with respect to smoking, diet score, and eGFR. Albeit not significantly, those with higher nut intake were younger. The metabolic syndrome and overweight/obesity were more frequently observed in the group with no or low nut intake, while the group reporting the consumption of $\geq 2$ weekly servings of nuts had better glycaemic control and lower systolic blood pressure, triglyceride concentration, waist circumference, and BMI.

In the generalized linear regression analyses, adjusted for age, sex, total energy intake, insulin dose, and physical activity, the continuous nut intake was negatively associated with the metabolic syndrome score, waist circumference, $\mathrm{HbA}_{1 \mathrm{c}}$, and BMI (Table 2). In addition, the consumption of $\geq 2$ weekly servings of nuts was associated with lower adjusted metabolic syndrome score, waist circumference, $\mathrm{HbA}_{1 \mathrm{c}}$, and $\mathrm{BMI}$, as compared to those with no or low intakes. These observations were repeated when comparing those reporting $<1$ and $\geq 1$ weekly servings (Supplementary Table S2). 
Table 1. Participant characteristics divided by the amount of nut consumption.

\begin{tabular}{|c|c|c|c|}
\hline & $\begin{array}{c}<2 \text { Weekly Servings } \\
n=902(85.3 \%)\end{array}$ & $\begin{array}{c}\geq 2 \text { Weekly Servings } \\
n=156(14.7 \%)\end{array}$ & $p$ \\
\hline Men \% & 42.9 & 34.0 & 0.043 \\
\hline Age, years & $47(36-57)$ & $43(34-55)$ & 0.054 \\
\hline Current smoker, \% & 11.8 & 8.0 & 0.208 \\
\hline Diet score & $11(9-14)$ & $11(9-14)$ & 0.811 \\
\hline Energy intake, MJ & $7.6(6.4-9.1)$ & $8.4(7.3-9.8)$ & $<0.001$ \\
\hline Physical activity, METmin/d & $283(154-465)$ & $344(210-593)$ & $<0.001$ \\
\hline Insulin dose $/ \mathrm{kg}$ & $0.58(0.46-0.75)$ & $0.51(0.38-0.65)$ & $<0.001$ \\
\hline $\mathrm{eGFR}, \mathrm{ml} / \mathrm{min} / 1.73 \mathrm{~m}^{2}$ & $100(86-112)$ & $101(89-111)$ & 0.392 \\
\hline Metabolic syndrome, $\%$ & 67.1 & 44.9 & $<0.001$ \\
\hline Metabolic syndrome score & $3(2-4)$ & $2(2-4)$ & $<0.001$ \\
\hline SBP, $\mathrm{mmHg}$ & $135(123-149)$ & $131(122-144)$ & 0.008 \\
\hline $\mathrm{DBP}, \mathrm{mmHg}$ & $77 \pm 9$ & $76 \pm 8$ & 0.205 \\
\hline Total cholesterol, $\mathrm{mmol} / \mathrm{L}$ & $4.6(4.0-5.2)$ & $4.5(3.9-5.1)$ & 0.282 \\
\hline HDL-cholesterol, mmol/L & $1.6(1.3-1.9)$ & $1.7(1.4-1.9)$ & 0.166 \\
\hline Triglycerides, mmol/L & $0.95(0.74-1.27)$ & $0.77(0.63-1.09)$ & $<0.001$ \\
\hline $\mathrm{HbA}_{1 \mathrm{c}}, \mathrm{mmol} / \mathrm{mol}$ & $64(56-72)$ & $58(51-66)$ & $<0.001$ \\
\hline $\mathrm{HbA}_{1 \mathrm{c}}, \%$ & $8.0(7.3-8.7)$ & $7.5(6.8-8.2)$ & $<0.001$ \\
\hline Waist circumference, $\mathrm{cm}$ & $88(80-97)$ & $83(75-91)$ & $<0.001$ \\
\hline Overweight/obese, \% & 57.1 & 43.6 & 0.002 \\
\hline BMI, $\mathrm{kg} / \mathrm{m}^{2}$ & $25.7(23.3-28.6)$ & $24.5(22.9-26.7)$ & $<0.001$ \\
\hline
\end{tabular}

Data are shown as frequency for categorical variables, median (interquartile range) for continuous variables with skewed distribution and mean \pm standard deviation for continuous variables with normal distribution. Between-group comparisons were conducted with Chi-squared test, Mann-Whitney U-test, and independent samples' $t$-test, respectively. One serving of nuts equals $28.4 \mathrm{~g}$. METmin/d, metabolic equivalent of task minutes per day; eGFR, estimated glomerular filtration rate; SBP, systolic blood pressure; DBP, diastolic blood pressure; $\mathrm{HbA}_{1 \mathrm{c}}$, glycated haemoglobin; overweight/obese, body mass index $\geq 25 \mathrm{~kg} / \mathrm{m}^{2}$; BMI, body mass index.

Table 2. Association between nut consumption and metabolic syndrome score, the continuous measures of the individual components of the metabolic syndrome, $\mathrm{HbA}_{1 \mathrm{c}}$, and body mass index.

\begin{tabular}{|c|c|c|c|c|c|}
\hline & Servings per Week & & $<2$ Weekly Servings & $\geq 2$ Weekly Servings & \\
\hline & B $(95 \%$ CI $)$ & $p$ & Mean $(95 \% \mathrm{CI})$ & Mean $(95 \% \mathrm{CI})$ & $p$ \\
\hline Metabolic syndrome score & $-0.051(-0.079--0.022)$ & $<0.001$ & $3.2(3.1-3.3)$ & $2.8(2.6-3.0)$ & $<0.001$ \\
\hline Waist circumference, $\mathrm{cm}$ & $-0.286(-0.562--0.010)$ & 0.042 & $89(88-90)$ & $86(84-88)$ & 0.005 \\
\hline $\mathrm{SBP}, \mathrm{mmHg}$ & $-0.343(-0.712-0.027)$ & 0.069 & $136(135-137)$ & $135(132-137)$ & 0.181 \\
\hline $\mathrm{DBP}, \mathrm{mmHg}$ & $-0.105(-0.322-0.112)$ & 0.342 & $77(76-77)$ & $76(74-77)$ & 0.462 \\
\hline Triglycerides, $\mathrm{mmol} / \mathrm{L}$ & $-0.004(-0.020-0.012)$ & 0.619 & $1.12(1.07-1.16)$ & $1.07(0.96-1.18)$ & 0.426 \\
\hline HDL-cholesterol, $\mathrm{mmol} / \mathrm{L}$ & $-0.004(-0.013-0.006)$ & 0.455 & $1.65(1.62-1.68)$ & $1.64(1.58-1.71)$ & 0.876 \\
\hline $\mathrm{HbA}_{1 \mathrm{c}}, \mathrm{mmol} / \mathrm{mol}$ & $-0.470(-0.777--0.162)$ & 0.003 & $65(64-66)$ & $60(58-62)$ & $<0.001$ \\
\hline BMI, $\mathrm{kg} / \mathrm{m}^{2}$ & $-0.103(-0.203--0.004)$ & 0.041 & $26.3(26.0-26.6)$ & $25.3(24.6-26.0)$ & 0.008 \\
\hline
\end{tabular}

Generalized linear regression. Models are adjusted for age, sex, energy intake, insulin dosing, and physical activity. In addition, analyses with blood pressures as outcomes are adjusted for the use of antihypertensive medication, and analyses with lipid variables as outcomes are adjusted for the use of lipid-lowering medication. One serving of nuts equals $28.4 \mathrm{~g}$. CI, confidence interval; SBP, systolic blood pressure; DBP, diastolic blood pressure; BMI, body mass index.

In the multivariable logistic regression analyses, nut consumption, measured as a continuous variable, was negatively associated with the presence of metabolic syndrome, and its blood pressure, triglyceride, and HDL-cholesterol components, and suboptimal glycaemic control (Table 3). Compared to those with no or low nut consumption, individuals consuming $\geq 2$ weekly servings of nuts had $51.5 \%$ lower odds of suboptimal glycaemic control, $33.4 \%$ lower odds of overweight/obesity, and $51.8 \%$ lower odds of having metabolic syndrome. In addition, the odds of meeting the waist (by 37.3\%), blood pressure (by $44.5 \%$ ), triglyceride (by $37.7 \%$ ), and HDL-cholesterol (by 36.2\%) components of the metabolic syndrome were significantly lower in those with higher nut intake. When comparing individuals reporting the consumption of $<1$ and $\geq 1$ weekly servings of nuts, the odds of 
metabolic syndrome, the blood pressure component, suboptimal glycaemic control, and overweight/obesity were lower in those with higher intake (Supplementary Table S3).

Table 3. Association between nut consumption and metabolic syndrome, its individual components, and overweight/obesity.

\begin{tabular}{|c|c|c|c|c|c|}
\hline & Servings Per Week & & $<2$ Weekly Servings & $\geq 2$ Weekly Servings & \\
\hline & B $(95 \%$ CI $)$ & $p$ & & B $(95 \%$ CI) & $p$ \\
\hline Metabolic syndrome & $0.915(0.866-0.968)$ & 0.002 & Ref. & $0.482(0.324-0.718)$ & $<0.001$ \\
\hline Waist component & 0.957 (0.909-1.007) & 0.090 & Ref. & $0.627(0.434-0.905)$ & 0.013 \\
\hline BP component & $0.913(0.861-0.967)$ & 0.002 & Ref. & $0.555(0.362-0.851)$ & 0.007 \\
\hline Triglyceride component & $0.925(0.870-0.984)$ & 0.013 & Ref. & $0.623(0.407-0.952)$ & 0.029 \\
\hline HDL-cholesterol component & $0.940(0.888-0.996)$ & 0.036 & Ref. & $0.638(0.424-0.958)$ & 0.030 \\
\hline Suboptimal glycaemic control & $0.936(0.891-0.983)$ & 0.008 & Ref. & $0.485(0.340-0.693)$ & $<0.001$ \\
\hline Overweight/obesity & $0.955(0.909-1.002)$ & 0.063 & Ref. & $0.666(0.467-0.950)$ & 0.025 \\
\hline
\end{tabular}

Logistic regression analysis. Models are adjusted for age, sex, total energy intake, insulin dose, and physical activity. One serving of nuts equals 28.4 g. CI, confidence interval; Ref., reference; BP, blood pressure; suboptimal glycaemic control, $\mathrm{HbA}_{1 \mathrm{c}}>59 \mathrm{mmol} / \mathrm{mol}(>7.5 \%)$; overweight/obesity, body mass index $\geq 25 \mathrm{~kg} / \mathrm{m}^{2}$.

\section{Discussion}

In this study, the consumption of nuts equaling or exceeding two weekly doses (i.e., $\geq 56.8 \mathrm{~g}$ ) was associated with reduced odds of meeting the criteria for the metabolic syndrome and all its individual components in adult individuals with type 1 diabetes. In addition, compared to those with no or low nut intake, the odds of good glycaemic control and normal body weight were significantly higher in those reporting the consumption of at least two weekly doses. Notably, lower doses were also beneficial as the consumption of at least one weekly serving was associated with lower odds of metabolic syndrome, the blood pressure component, suboptimal glycaemic control, and overweight or obesity.

To the best of our knowledge, the association between nut intake and metabolic syndrome in individuals with type 1 diabetes has not been previously investigated. However, studies in other populations are available. For example, in the cross-sectional analyses of the Prevención con Dieta Mediterránea (PREDIMED) trial, among individuals with high cardiovascular disease risk, compared to those reporting the consumption of less than one serving of nuts per week, those with over three weekly servings had lower odds of the metabolic syndrome [10]. Following the randomization of the PREDIMED study participants into a Mediterranean diet supplemented with virgin olive oil, a Mediterranean diet supplemented with mixed nuts, or a low-fat diet, those in the group supplementing with nuts had a significantly reduced prevalence of the metabolic syndrome after one year [17]. In the prospective SUN Project of 9887 university graduates initially free of metabolic syndrome, individuals consuming $\geq 2$ servings of nuts per week presented a $32 \%$ lower risk of developing the metabolic syndrome after 6 years of follow-up compared to those who never or almost never consumed nuts [11].

Independent of factors such as total energy intake and physical activity, we observed lower BMI, lower odds of overweight/obesity, lower waist circumference, and lower odds of meeting the waist component of the metabolic syndrome in those with higher nut consumption. Moreover, in the cross-sectional analysis of the PREDIMED study, higher nut consumption was associated with lower odds of obesity and lower odds of fulfilling the criteria for abdominal obesity [10], and after one year into the study, the prevalence of the waist component of the metabolic syndrome was reduced in the supplemental nut group as compared to the low-fat group [17]. In the National Health and Nutrition Examination Survey (NHANES), compared to non-consumption, nut consumption was associated with a $12 \%$ lower risk of overweight or obesity [18]. In the Nurses' Health Study, women who reported eating nuts $\geq 2$ times per week had lower mean weight gain and lower risk of obesity over the 8-year follow-up, compared to those who rarely ate nuts [19]. However, two meta-analyses of intervention studies concluded that nut consumption had no impact on waist circumference [20] or body weight [21]. 
In the current study, higher nut consumption was not associated with the continuous measures of systolic or diastolic blood pressure but was associated with lower odds of meeting the blood pressure component of the metabolic syndrome. Contrary to our observations, no association between nut consumption and the blood pressure component was observed in the cross-sectional analyses of the PREDIMED data [10]. However, at a oneyear follow-up, individuals supplementing with nuts exhibited a reduced prevalence of high blood pressure relative to the low-fat group [17]. In the NHANES, nut consumption, as compared to non-consumption, was associated with a $13 \%$ lower risk of hypertension [18]. Among participants in the Physicians' Health Study, free from hypertension at the baseline and relative to individuals reporting no nut consumption, those reporting consuming nuts $\geq 7$ times per week had reduced odds of incident hypertension [22]. However, after adjusting for BMI, an inverse relation between nut intake and hypertension was only evident in lean subjects. Similarly, in the SUN prospective cohort, followed up for a median of 4.3 years, self-reported nut intake was not associated with incident hypertension [23]. While a number of meta-analyses of controlled interventions have reported no effect of nut intake on blood pressure [20,24,25], in their meta-analysis Mohammadifard et al. concluded that nut consumption led to a significant reduction in systolic blood pressure only in individuals without type 2 diabetes, but not in the total population [26].

The odds of meeting both the triglyceride and HDL-cholesterol components of the metabolic syndrome in this study were significantly lower in those reporting higher nut intakes. However, nut intake was not associated with the continuous measurements of these lipid variables. While no cross-sectional associations were observed between nut intake and dyslipidaemia in the PREDIMED study [10], the prevalence of elevated triglyceride concentration was reduced in the nut-supplemented individuals one year after the commencement of the intervention [17]. Compared to the non-consumers in the NHANES, those reporting nut consumption had a $20 \%$ lower risk of low HDL-cholesterol concentration [18]. Instead, in the Nurses' Health Study, nut consumption was not related to HDLcholesterol concentration, but higher intakes were associated with lower LDL-cholesterol, non-HDL-cholesterol, total cholesterol, and apolipoprotein B-100 concentrations [27]. In a meta-analysis of randomized controlled trials of tree-nut interventions, reduction in triglyceride concentration was observed with no changes evident in the HDL-cholesterol concentration [20]. Finally, in another meta-analysis including trials with walnut-enriched diets, reductions in total cholesterol, LDL-cholesterol, and triglyceride concentrations, as compared to a control diet, were reported [25].

Of specific importance to individuals with type 1 diabetes, we observed better glycaemic control with increasing nut intake. While a number of previous trials have shown reduced post-prandial blood glucose concentrations related to nut consumption, suggestive of at least a short-term beneficial glycaemic effect [28-30], the effects on other measures of glucose control are mixed. For example, in the cross-sectional analyses of the PREDIMED data, nut consumption was not associated with the fasting blood glucose concentration but compared to individuals consuming less than one weekly serving of nuts, those with over three weekly servings had lower odds of diabetes [10]. Moreover, in a meta-analysis of 12 randomized controlled trials including participants with type 2 diabetes, a median daily consumption of $56 \mathrm{~g}$ of tree nuts for a median duration of 8 weeks significantly reduced $\mathrm{HbA}_{1 \mathrm{c}}$ and fasting glucose concentration compared to the control diets but had no effects on fasting insulin and HOMA-IR [31]. Instead, in another meta-analysis of randomized controlled trials with a 3-month median intervention duration, the consumption of tree nuts and peanuts was beneficially associated with HOMA-IR and fasting insulin concentration but had no effect on fasting blood glucose concentration or $\mathrm{HbA}_{1 \mathrm{c}}$ [32]. Yet, in another meta-analysis of randomized controlled trials, walnut consumption had no impact on the markers of blood glucose control, including fasting glucose, $\mathrm{Hb}_{1 \mathrm{c}}$, fasting insulin, and HOMA-IR [33].

Several mechanisms may explain the health benefits related to nut consumption. For example, in a meta-analysis of 23 randomized controlled trials, long-term ( $\geq 12$ week) nut 
intake significantly reduced the concentrations of the intercellular adhesion molecule and the vascular cell adhesion molecule [34], particles involved in inflammatory processes. Various phytosterols found in nuts likely interfere with cholesterol absorption and thus have the potential to bring about cholesterol-lowering effects [35]. Moreover, especially when replacing saturated fatty acids, the high unsaturated fatty acid content of nuts has the potential to beneficially impact the lipid profile [36]. Phenolic acids attenuate oxidative stress, leading to blood pressure lowering through improved endothelial function and nitric oxide bioavailability in the arterial vasculature [37]. Important for weight control, nut consumption has been shown to reduce glycaemic response and increase satiety [38]. Finally, nut consumption has also been associated with an increased relative abundance of the genera Clostridium, Lachnospira, and Roseburia [39] in the gut, all of which are known butyrate producers [40]. Butyrate, on the other hand, is an important source of energy for intestinal colonocytes and plays a role in the regulation of cell proliferation and differentiation [41].

A large and well-defined sample of individuals with type 1 diabetes and the use of a food record, devoid of recall bias, to assess dietary intake are the major strengths of this study. However, the study is observational and does not allow the assessment of causeeffect relations. In addition, as is the case in epidemiological trials, some selection bias may have taken place as individuals who are more interested in their health are more likely to take part in health-related studies. Indeed, those not completing the food record had an overall worse health profile compared to those included in this study. The likely effect of this bias is the dilution of the current observations. It should also be noted that there are no universally accepted cut-off values for dichotomizing individuals into those with high and low nut intakes. The current decision to divide the sample into those reporting $<2$ or $\geq 2$ weekly servings was based on the previous literature [11,19] and may be considered somewhat arbitrary. However, for sensitivity analyses, we additionally divided the sample into those reporting $<1$ or $\geq 1$ weekly servings and observed that most of the original observations remained statistically significant. Finally, nut consumption may be associated with an overall healthy lifestyle, and while we considered several important confounders, the potential of residual confounding cannot be ruled out.

\section{Conclusions}

In conclusion, in individuals with type 1 diabetes this is the first time it has been shown that nut consumption is associated with reduced odds of the metabolic syndrome and all its individual components. While intervention trials are needed to establish the potential causal role of nuts for the health of individuals with type 1 diabetes, incorporating nuts in an overall healthy diet may well be already justified at this stage.

Supplementary Materials: The following are available online at https:/ / www.mdpi.com/article/ 10.3390/nu13113909/s1, Supplementary information of The Finnish Diabetic Nephropathy Study Centers. Table S1: Comparison of individuals in the FinnDiane Study completing and not completing the food record, Table S2: Association between nut consumption and metabolic syndrome score, the continuous measures of the individual components of the metabolic syndrome, $\mathrm{HbA1c}$, and body mass index. Table S3: Association between nut consumption and metabolic syndrome, its individual components, and overweight/obesity.

Author Contributions: Conceptualization, A.J.A. and P.-H.G.; formal analysis, A.J.A.; investigation, A.J.A.; resources, P.-H.G.; writing—original draft preparation, A.J.A.; writing-review and editing, C.M.F., V.H. and P.-H.G.; supervision, P.-H.G.; funding acquisition, V.H. and P.-H.G. All authors have read and agreed to the published version of the manuscript.

Funding: This study was supported by grants from the Academy of Finland (grant number 316664); the Novo Nordisk Foundation (\#NNF OC0013659); the Signe and Ane Gyllenberg Foundation; the Folkhälsan Research Foundation; Helsinki University Hospital Research Funds (TYH2018207); the Wilhelm and Else Stockmann Foundation; the Liv och Hälsa Society; and the Päivikki and Sakari Sohlberg Foundation. The funding agencies did not contribute to the study design, conduct of the 
study, analysis of samples or data, interpretation of the findings, writing of the manuscript, or in the decision to submit the manuscript for publication.

Institutional Review Board Statement: The study was conducted according to the guidelines of the Declaration of Helsinki and approved by the Ethics Committee of Helsinki and Uusimaa Hospital District (Ethics committee reference number 491/E5/06).

Informed Consent Statement: Informed consent was obtained from all subjects involved in the study.

Data Availability Statement: According to the General Data Protection Regulation of the European Union (679/2016), the principles of data protection should apply to any information concerning an identified or identifiable natural person and that personal data which have undergone pseudonymization, which could be attributed to a natural person by the use of additional information should be considered to be information on an identifiable natural person. Thus, according to the GDPR, all pseudonymized data are considered personal data and cannot be published openly.

Acknowledgments: The skilled technical assistance of Anna Sandelin, Mira Korolainen, and Jaana Tuomikangas is gratefully acknowledged. The authors also acknowledge all the physicians and nurses at each center participating in the recruitment of patients (Supplementary information of The Finnish Diabetic Nephropathy Study Centers).

Conflicts of Interest: Per-Henrik Groop has received investigator-initiated grants from Eli Lilly and Roche and is an advisory board member for AbbVie, Astellas, Astra Zeneca, Bayer, BoehringerIngelheim, Eli Lilly, Janssen, Medscape, MSD, Mundipharma, Novartis, Novo Nordisk, and Sanofi. He has received lecture honoraria from Astellas, Astra Zeneca, Boehringer-Ingelheim, Eli Lilly, Elo Water, Genzyme, Medscape, MSD, Mundipharma, Novartis, Novo Nordisk, PeerVoice, Sanofi and Sciarc. All the other authors declare no conflict of interest.

\section{References}

1. Ros, E. Health benefits of nut consumption. Nutrients 2010, 2, 652-682. [CrossRef]

2. Afshin, A.; Micha, R.; Khatibzadeh, S.; Mozaffarian, D. Consumption of nuts and legumes and risk of incident ischemic heart disease, stroke, and diabetes: A systematic review and meta-analysis. Am. J. Clin. Nutr. 2014, 100, 278-288. [CrossRef]

3. Albert, C.M.; Gaziano, J.M.; Willett, W.C.; Manson, J.E. Nut consumption and decreased risk of sudden cardiac death in the Physicians' Health Study. Arch. Intern. Med. 2002, 162, 1382-1387. [CrossRef] [PubMed]

4. Liu, G.; Guasch-Ferré, M.; Hu, Y.; Li, Y.; Hu, F.B.; Rimm, E.B.; Manson, J.E.; Rexrode, K.M.; Sun, Q. Nut consumption in relation to cardiovascular disease incidence and mortality among patients with diabetes mellitus. Circ. Res. 2019, 124, 920-929. [CrossRef]

5. US. Food and Drug Administration (FDA). Qualified Health Claims: Letter of Enforcement Discretion-Nuts and Coronary Heart Disease (Docket No 02P-0505). 2003. Available online: http://wayback.archive-it.org/7993/20171114183724/https: / / www.fda.gov/Food/IngredientsPackagingLabeling/LabelingNutrition/ucm072926.htm (accessed on 6 October 2021).

6. Saklayen, M.G. The global epidemic of the metabolic syndrome. Curr. Hypertens. Rep. 2018, 20, 12. [CrossRef]

7. Alberti, K.G.; Eckel, R.H.; Grundy, S.M.; Zimmet, P.Z.; Cleeman, J.I.; Donato, K.A.; Fruchart, J.C.; James, W.P.T.; Loria, C.M.; Smith S.C., Jr. Harmonizing the metabolic syndrome: A joint interim statement of the International Diabetes Federation Task Force on Epidemiology and Prevention; National Heart, Lung, and Blood Institute; American Heart Association; World Heart Federation; International Atherosclerosis Society; and International Association for the Study of Obesity. Circulation 2009, 120, $1640-1645$.

8. Thorn, L.M.; Forsblom, C.; Fagerudd, J.; Thomas, M.C.; Pettersson-Fernholm, K.; Saraheimo, M.; Wadén, J.; Rönnback, M.; Rosengård-Bärlund, M.; Af Björkesten, C.G.; et al. Metabolic Syndrome in Type 1 Diabetes: Association with diabetic nephropathy and glycemic control (the FinnDiane study). Diabetes Care 2005, 28, 2019-2024. [CrossRef] [PubMed]

9. DiMeglio, L.A.; Evans-Molina, C.; Oram, R.A. Type 1 diabetes. Lancet 2018, 391, 2449-2462. [CrossRef]

10. Ibarrola-Jurado, N.; Bulló, M.; Guasch-Ferré, M.; Ros, E.; Martínez-González, M.A.; Corella, D.; Fiol, M.; Wärnberg, J.; Estruch, R.; Román, P.; et al. Cross-sectional assessment of nut consumption and obesity, metabolic syndrome and other cardiometabolic risk factors: The PREDIMED Study. PLoS ONE 2013, 8, e57367. [CrossRef]

11. Fernández-Montero, A.; Bes-Rastrollo, M.; Beunza, J.J.; Barrio-Lopez, M.T.; de la Fuente-Arrillaga, C.; Moreno-Galarraga, L.; Martínez-González, M.A. Nut consumption and incidence of metabolic syndrome after 6-year follow-up: The SUN (Seguimiento Universidad de Navarra, University of Navarra Follow-up) cohort. Public Health Nutr. 2013, 16, 2064-2072. [CrossRef]

12. Ahola, A.J.; Thorn, L.M.; Saraheimo, M.; Forsblom, C.; Groop, P.-H. on behalf of the Finndiane Study Group. Depression is associated with the metabolic syndrome among patients with type 1 diabetes. Ann. Med. 2010, 42, 495-501. [CrossRef]

13. Levey, A.S.; Stevens, L.A.; Schmid, C.H.; Zhang, Y.; Castro, A.F., III; Feldman, H.I.; Kusek, J.W.; Eggers, P.; Van Lente, F.; Greene, T.; et al. A new equation to estimate glomerular filtration rate. Ann. Intern. Med. 2009, 150, 604-612. [CrossRef] [PubMed]

14. Ahola, A.J.; Mikkilä, V.; Mäkimattila, S.; Forsblom, C.; Freese, R.; Groop, P.-H. Energy and nutrient intakes and adherence to dietary guidelines among Finnish adults with type 1 diabetes. Ann. Med. 2012, 44, 73-81. [CrossRef] 
15. Ahola, A.J.; Lassenius, M.; Forsblom, C.; Harjutsalo, V.; Lehto, M.; Groop, P.-H. Dietary patterns reflecting healthy food choices are associated with lower serum LPS activity. Sci. Rep. 2017, 7, 6511-6519. [CrossRef]

16. Ahola, A.J.; Mikkilä, V.; Saraheimo, M.; Wadén, J.; MäkimaTtila, S.; Forsblom, C.; Freese, R.; Groop, P.H. Sense of coherence, food selection and leisure time physical activity in type 1 diabetes. Scand. J. Public Health 2012, 40, 621-628. [CrossRef] [PubMed]

17. Salas-Salvadó, J.; Fernández-Ballart, J.; Ros, E.; Martínez-González, M.A.; Fitó, M.; Estruch, R.; Corella, D.; Fiol, M.; Gómez-Gracia, E.; Arós, F.; et al. Effect of a Mediterranean diet supplemented with nuts on metabolic syndrome status: One-year results of the PREDIMED Randomized Trial. Arch. Intern. Med. 2008, 168, 2449-2458. [CrossRef] [PubMed]

18. O'Neil, C.E.; Keast, D.R.; Nicklas, T.A.; Fulgoni, V.L. Nut consumption is associated with decreased health risk factors for cardiovascular disease and metabolic syndrome in U.S. adults: NHANES 1999-2004. J. Am. Coll. Nutr. 2011, 30, 502-510. [CrossRef] [PubMed]

19. Bes-Rastrollo, M.; Wedick, N.M.; Martinez-Gonzalez, M.A.; Li, T.Y.; Sampson, L.; Hu, F.B. Prospective study of nut consumption, long-term weight change, and obesity risk in women. Am. J. Clin. Nutr. 2009, 89, 1913-1919. [CrossRef]

20. Mejia, S.B.; Kendall, C.W.; Viguiliouk, E.; Augustin, L.S.; Ha, V.; Cozma, A.I.; Mirrahimi, A.; Maroleanu, A.; Chiavaroli, L.; Leiter, L.A.; et al. Effect of tree nuts on metabolic syndrome criteria: A systematic review and meta-analysis of randomised controlled trials. BMJ Open 2014, 4, e004660. [CrossRef]

21. Kim, Y.; Keogh, J.; Clifton, P. Nuts and cardio-metabolic disease: A review of meta-analyses. Nutrients 2018, 10, 1935. [CrossRef]

22. Djoussé, L.; Rudich, T.; Gaziano, J.M. Nut consumption and risk of hypertension in US male physicians. Clin. Nutr. 2009, 28, 10-14. [CrossRef] [PubMed]

23. Martínez-Lapiscina, E.H.; Pimenta, A.M.; Beunza, J.J.; Bes-Rastrollo, M.; Martínez, J.A.; Martínez-González, M.A. Nut consumption and incidence of hypertension: The SUN prospective cohort. Nutr. Metab. Cardiovasc. Dis. 2010, 20, 359-365. [CrossRef]

24. Del Gobbo, L.C.; Falk, M.C.; Feldman, R.; Lewis, K.; Mozaffarian, D. Effects of tree nuts on blood lipids, apolipoproteins, and blood pressure: Systematic review, meta-analysis, and dose-response of 61 controlled intervention trials. Am. J. Clin. Nutr. 2015, 102, 1347-1356. [CrossRef] [PubMed]

25. Guasch-Ferré, M.; Li, J.; Hu, F.B.; Salas-Salvadó, J.; Tobias, D.K. Effects of walnut consumption on blood lipids and other cardiovascular risk factors: An updated meta-analysis and systematic review of controlled trials. Am. J. Clin. Nutr. 2018, 108, 174-187. [CrossRef]

26. Mohammadifard, N.; Salehi-Abargouei, A.; Salas-Salvadó, J.; Guasch-Ferré, M.; Humphries, K.; Sarrafzadegan, N. The effect of tree nut, peanut, and soy nut consumption on blood pressure: A systematic review and meta-analysis of randomized controlled clinical trials. Am. J. Clin. Nutr. 2015, 101, 966-982. [CrossRef]

27. Li, T.Y.; Brennan, A.M.; Wedick, N.M.; Mantzoros, C.; Rifai, N.; Hu, F.B. Regular consumption of nuts is associated with a lower risk of cardiovascular disease in women with type 2 diabetes. J. Nutr. 2009, 139, 1333-1338. [CrossRef]

28. Kendall, C.W.C.; Esfahani, A.; Josse, A.R.; Augustin, L.S.A.; Vidgen, E.; Jenkins, D.J.A. The glycemic effect of nut-enriched meals in healthy and diabetic subjects. Nutr. Metab. Cardiovasc. Dis. 2011, 21, S34-S39. [CrossRef]

29. Kendall, C.W.C.; Josse, A.R.; Esfahani, A.; Jenkins, D.J.A. The impact of pistachio intake alone or in combination with highcarbohydrate foods on post-prandial glycemia. Eur. J. Clin. Nutr. 2011, 65, 696-702. [CrossRef] [PubMed]

30. Josse, A.R.; Kendall, C.W.C.; Augustin, L.S.A.; Ellis, P.R.; Jenkins, D.J.A. Almonds and postprandial glycemia-A dose-response study. Metabolism 2007, 56, 400-404. [CrossRef] [PubMed]

31. Viguiliouk, E.; Kendall, C.W.; Blanco Mejia, S.; Cozma, A.I.; Ha, V.; Mirrahimi, A.; Jayalath, V.H.; Augustin, L.S.; Chiavaroli, L.; Leiter, L.A.; et al. Effect of tree nuts on glycemic control in diabetes: A systematic review and meta-analysis of randomized controlled dietary trials. PLoS ONE 2014, 9, e103376. [CrossRef]

32. Tindall, A.M.; Johnston, E.A.; Kris-Etherton, P.M.; Petersen, K.S. The effect of nuts on markers of glycemic control: A systematic review and meta-analysis of randomized controlled trials. Am. J. Clin. Nutr. 2019, 109, 297-314. [CrossRef]

33. Neale, E.P.; Guan, V.; Tapsell, L.C.; Probst, Y.C. Effect of walnut consumption on markers of blood glucose control: A systematic review and meta-analysis. Br. J. Nutr. 2020, 124, 641-653. [CrossRef] [PubMed]

34. Xiao, Y.; Xia, J.; Ke, Y.; Cheng, J.; Yuan, J.; Wu, S.; Lv, Z.; Huang, S.; Kim, J.H.; Wong, S.Y.S.; et al. Effects of nut consumption on selected inflammatory markers: A systematic review and meta-analysis of randomized controlled trials. Nutrition 2018, 54, 129-143. [CrossRef] [PubMed]

35. Segura, R.; Javierre, C.; Lizarraga, M.A.; Ros, E. Other relevant components of nuts: Phytosterols, folate and minerals. Br. J. Nutr. 2006, 96, S36-S44. [CrossRef] [PubMed]

36. Mensink, R.P.; Zock, P.L.; Kester, A.D.; Katan, M.B. Effects of dietary fatty acids and carbohydrates on the ratio of serum total to HDL cholesterol and on serum lipids and apolipoproteins: A meta-analysis of 60 controlled trials. Am. J. Clin. Nutr. 2003, 77, 1146-1155. [CrossRef] [PubMed]

37. Zhao, Y.; Wang, J.; Ballevre, O.; Luo, H.; Zhang, W. Antihypertensive effects and mechanisms of chlorogenic acids. Hypertens. Res. 2012, 35, 370-374. [CrossRef]

38. Zibella, M.; Parillo, M. Effects of nuts on postprandial glycemia, satiety and hunger sensations in healthy individuals. MNM 2017, 10, 243-249. [CrossRef]

39. Creedon, A.C.; Hung, E.S.; Berry, S.E.; Whelan, K. Nuts and their effect on gut microbiota, gut function and symptoms in adults: A systematic review and meta-analysis of randomised controlled trials. Nutrients 2020, 12, 2347. [CrossRef] 
40. Wang, B.; Zhu, S.; Liu, Z.; Wei, H.; Zhang, L.; He, M.; Pei, F.; Zhang, J.; Sun, Q.; Duan, L. Increased expression of colonic mucosal melatonin in patients with irritable bowel syndrome correlated with gut dysbiosis. Genom. Proteom. Bioinform. 2021, 18, 708-720. [CrossRef]

41. Wong, J.M.W.; de Souza, R.; Kendall, C.W.C.; Emam, A.; Jenkins, D.J.A. Colonic health: Fermentation and short chain fatty acids. J. Clin. Gastroenterol. 2006, 40, 235-243. [CrossRef] 